\section{Bilateral acute depigmentation of the iris (BADI): first reported case in Brazil}

\section{Dear Editor}

We have read with considerable interest the article entitled " $\mathrm{Bi}$ lateral acute depigmentation of the iris (BADI): first reported case in Brazil", by Maestrini et al.(1). The authors describe a patient who was diagnosed as having BADI, which has attracted a lot of attention among ophthalmologists in recent years. We would like to thank the authors for reporting on this interesting case, and we want to contribute further by making the following three points.

Bilateral acute iris transillumination (BAIT) and BADI are both relatively new clinical entities and share some important features: an acute onset of severe photophobia and red eyes after a flu-like syndrome, pigment dispersion into the anterior chamber, and exclusive involvement of the iris. However, in patients who have BAIT the pigment discharge is from the iris pigment epithelium, whereas for those with BADI, the pigment discharge comes from the iris stroma. This leads to iris transillumination defects and mydriatic/atonic pupilla in patients with BAIT, but not in those who have BADI.

First, the authors report that there are two clinical sub-types of BADI. The first sub-type has a more benign course, a lower incidence of increased intraocular pressure (IOP), and reversibility of the iris changes without transillumination defects or pupil distortion. The second sub-type, BAIT, has diffuse iris transillumination and mydriatic/ atonic pupilla or distorted pupil, occasional posterior synechiae, and increased IOP(1). Indeed, the first sub-type mentioned by the authors reflects the characteristic clinical features of the BADI (2), and the second sub-type, referred to in the study as BAIT, shares some properties with BADI but has differentiating characteristic features ${ }^{(3)}$. In addition, BAIT was first described by Tugal-Tutkun et al. as being a probable distinct entity ${ }^{(3)}$, and several publications have subsequently reported it as being a distinct entity from the BADI ${ }^{(4,5)}$. It is not clear, therefore, whether BAIT is a sub-type of the BADI. It appears to be a different entity or an expanded spectrum of BADI, which makes it incorrect to describe BAIT as a sub-type of BADI.

In addition, Maestrini et al. ${ }^{(1)}$ report that both conditions have a self-limited course and a good prognosis. However, BAIT cases may present with severe IOP rise, which is sometimes resistant to medical treatment and necessitates trabeculectomy surgery as in our case report ${ }^{(5)}$. Therefore, clinicians should be aware of a severe IOP rise in patients with BAIT during their follow-up.

Finally, although the exact etiopathogenesis of BAIT remains unclear, several publications have reported a relationship between BAIT and systemic use of moxifloxacin ${ }^{(4)}$, upper respiratory tract infections ${ }^{(3)}$, and a toxic effect following a fumigation therapy ${ }^{(5)}$. Maestrini et al. ${ }^{(1)}$ reported the cause of BADI may be a viral etiology considering empirical antiviral therapy has provided some clinical improvement by reducing pigment dispersion into the anterior chamber. However, these authors should have taken an aqueous sample for viral analysis in order to conclude such a relationship. Therefore, further study is needed to include the aqueous tap for local antibody production against the virus, or to demonstrate the viral DNA to clarify the viral etiology in patients with BAIT.

\section{Saban Gonul', Banu Bozkurt}

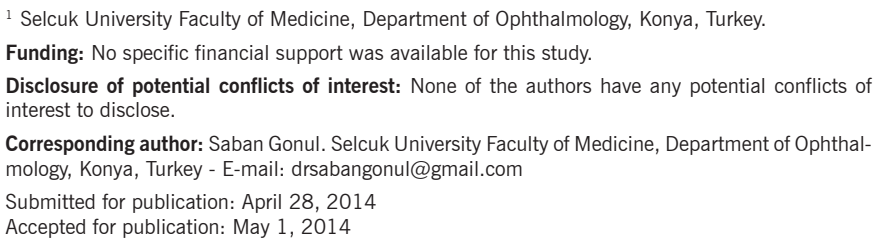

\section{REFERENCES}

1. Maestrini HA, Maestrini AA, Machado Dde O, Santos DV, Almeida HG. Bilateral acute depigmentation of the iris (BADI): first reported case in Brazil. Arq Bras Oftalmol. 2013; 76(1):42-4.

2. Tugal-Tutkun I, Araz B, Taskapili M, Akova YA, Yalniz-Akkaya Z, Berker N, et al. Bilateral acute depigmentation of the iris: report of 26 new cases and four-year follow-up of two patients. Ophthalmology. 2009;116(8):1552-7.

3. Tugal-Tutkun I, Onal S, Garip A, Taskapili M, Kazokoglu H, Kadayifcilar S, et al. Bilateral acute iris transillumination. Arch Ophthalmol. 2011;129(10):1312-19.

4. Morshedi RG, Bettis DI, Moshirfar M, Vitale AT. Bilateral acute iris transillumination following systemic moxifloxacin for respiratory illness: report of two cases and review of the literature. Ocul Immunol Inflamm. 2012;20(4):266-72.

5. Gonul S, Bozkurt B, Okudan S, Tugal-Tutkun I. Bilateral acute iris transillumination following a fumigation therapy: a village-based traditional method for the treatment of ophthalmomyiasis. Cutan Ocul Toxicol. 2014 Mar 31. [Epub ahead of print]. doi: 10.3109/15569527.2014.886589

\section{Reply}

\section{Dear Editor,}

We were happy to receive the letter from Dr. Saban Gonul, who resides in Turkey, concerning our article titled "Bilateral acute depigmentation of the iris (BADI): first reported case in Brazil". The vast majority of BADI and bilateral acute iris transillumination (BAIT) cases have occurred in Turkey; therefore, it is very important to listen to researchers experienced with this fascinating new clinical entity.

Dr. Gonul suggests that it would be incorrect to describe BAIT as a subtype of BADI. However, both are new clinical entities that share many important features, such as an acute onset of severe bilateral photophobia and red eyes, pigment discharge in the anterior chamber, heavy pigment deposition in the trabecular meshwork, and a marked symptom relief with topical corticosteroids. In addition, both are more common in women, and in many cases, it occurs after a flu-like illness and many patients have histories of previous antibiotic use, particularly moxifloxacin. It is not yet clear if they are distinct entities or subtypes of the same disease. The fact that both share so many features gives strong support to the idea that they are subtypes of the same disease. Tugal-Tutkun et al. (2011) published the first and most important study on BAIT, with 26 cases $^{(1)}$. In their conclusion, the authors state very clearly that BAIT might be a new entity or might represent an expanded spectrum of BADI. This question has not yet been answered and further research is needed to clarify this point.

Indeed BAIT is more severe than BADI, as we pointed out in our paper. BADI has a more benign course, a shorter duration of pigment discharge, a lower incidence of elevated intraocular pressure (IOP) that is only transient, and sometimes reversible iris changes. BAIT is frequently associated with an early, severely elevated IOP, and the iris changes are usually irreversible. A few cases of BAIT might need a trabeculectomy to control an intractably elevated IOP. In Tugal-Tutkun et al. (2011), 2 of 26 patients needed a bilateral trabeculectomy ${ }^{(1)}$. Although both BADI and BAIT are self-limited, we agree with Dr. Gonul that clinicians should be aware of the possibility of a severe, intractable elevation in IOP and a longer duration of disease in cases of BAIT.

Finally, the exact etiopathogenesis of BADI and BAIT remain unclear. All previous studies ${ }^{(1-3)}$ have entertained the viral hypothesis. The fact that many cases of BADI and BAIT occur after a flu-like illness or upper respiratory tract infection, with or without the use of antibiotics, suggests a relationship with some kind of infection, viral or not. In the first paper on BADI, Tugal-Tutkun et al. (2006) suggested that it represents a new entity or an unusual presentation of herpetic eye disease ${ }^{(2)}$. In Tugal-Tutkun et al. (2009)(3), viral serology was performed in 10 of 26 cases of BADI, and all 10 had lgG antibodies against cytomegalovirus (CMV). Consequently, the authors proposed that BADI be considered part of an expanded spectrum of CMV-related ocular 
diseases. Five patients in that series had histories of recurrent fever blisters. In Tugal-Tutkun et al. (2011)(1), 83\% of BAIT patients tested were seropositive for IgG antibodies against herpes simplex virus type 1 and 75\% were positive for Epstein-Barr virus IgG antibodies. All patients tested for anti-varicella zoster virus and CMV were found to have IgG antibodies. The authors hypothesized that BAIT represents a condition triggered by a viral infection. In Weffers Bettink-Remeijer et al. (2009)(4), the herpetic genome was positive in the aqueous tap of one patient with BAIT. Furthermore, BAIT shares some features of viral herpetic iridocyclitis, in which ischemic necrosis of the iris results in iris atrophy, distortion of the pupil, and transillumination defects. In our study, a herpetic etiology cannot be ruled out because we did not have access to the analysis of intraocular specimens. We decided not to perform an anterior chamber tap to try polymerase chain reaction (PCR) for herpes viruses because PCR of aqueous humor is rather insensitive in the absence of posterior segment involvement ${ }^{(5)}$. A biopsy of the iris or cornea obtained during a trabeculectomy might be more elucidative. We preferred to institute empirical treatment with valacyclovir, which resulted in marked clinical improvement. Obviously, this is not proof of a viral etiology, but it is certainly suggestive. In conclusion, the etiopathogenesis of BADI remains to be eluci- dated, and we still have more questions than answers regarding this interesting and challenging new disease.

Heloisa Andrade Maestrini

Department of Glaucoma, Oculare Centro de Oftalmologia, Belo Horizonte, MG, Brazil.

Corresponding author: Heloisa Andrade Maestrini. Rua Maranhão, 65 - Belo Horizonte (MG) 30150-330 - Brazil - E-mail: heloisa.maestrini@gmail.com

\section{REFERENCES}

1. Tugal-Tutkun I, Onal S, Garip A, Taskapili M, Kazokoglu H, Kadayifcilar S, et al. Bilateral acute iris transillumination. Arch Ophthalmol. 2011;129(10):1312-9.

2. Tugal-Tutkun I, Urgancioglu M. Bilateral acute depigmentation of the iris. Graefes Arch Clin Exp Ophthalmol. 2006;244(6):742-6.

3. Tugal-Tutkun I, Araz B, Taskapili M, Akova YA, Yalniz-Akkaya Z, Berker N, et al. Bilateral acute depigmentation of the iris: report of 26 new cases and four-year follow-up of two patients. Ophthalmology. 2009;116(8):1552-7, 1557 e1.

4. Wefers Bettink-Remeijer M, Brouwers K, van Langenhove L, De Waard PW, Missotten TO, Martinez Ciriano JP, et al. Uveitis-like syndrome and iris transillumination after the use of oral moxifloxacin. Eye (Lond). 2009:23(12):2260-2.

5. Matos K, Muccioli C, Belfort Junior R, Rizzo LV. Correlation between clinical diagnosis and PCR analysis of serum, aqueous, and vitreous samples in patients with inflammatory eye disease. Arq Bras Oftalmol. 2007;70(1):109-14.

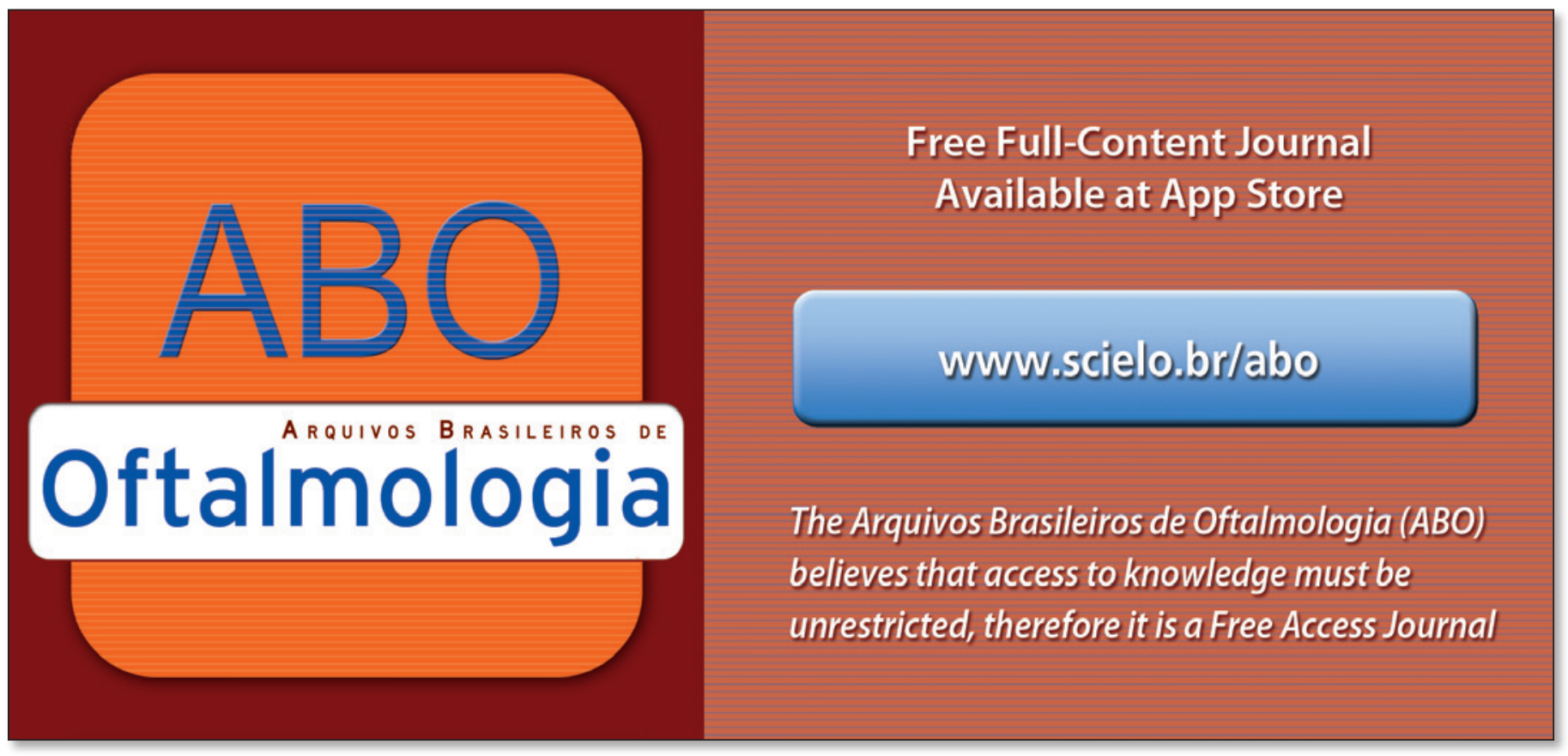

